\title{
Application of electrical resistivity imaging technique in slope stability study in Banding Island, Perak
}

\begin{abstract}
A landslide investigation using 2D electrical resistivity imaging (ERI) has been undertaken in the Banding Island, Perak. Banding Island is underlain by Baling Formation which consist of two main facies; namely Argillaceous Facie (eastern part) and Arenaceous Facie (western part). The eastern part of the island is relatively prone to landslide and slope failure. Detailed field resistivity imaging was carried on four lines along the eastern and western parts of the Banding Island. The inferred lithological depth sections based on electrical properties clearly differentiates between the different types of rocks.
\end{abstract}

Keyword: Electrical resistivity imaging (ERI); Banding Island; Resistivity imaging; Landslides 